\title{
Real-Time simulation of static synchronous condenser for compensation of reactive power
}

\author{
Abdellatif Hinda, Mounir Khiat \\ Department of Electrical Engineering, Ecole Nationale Polytechnique d'Oran, Algeria
}

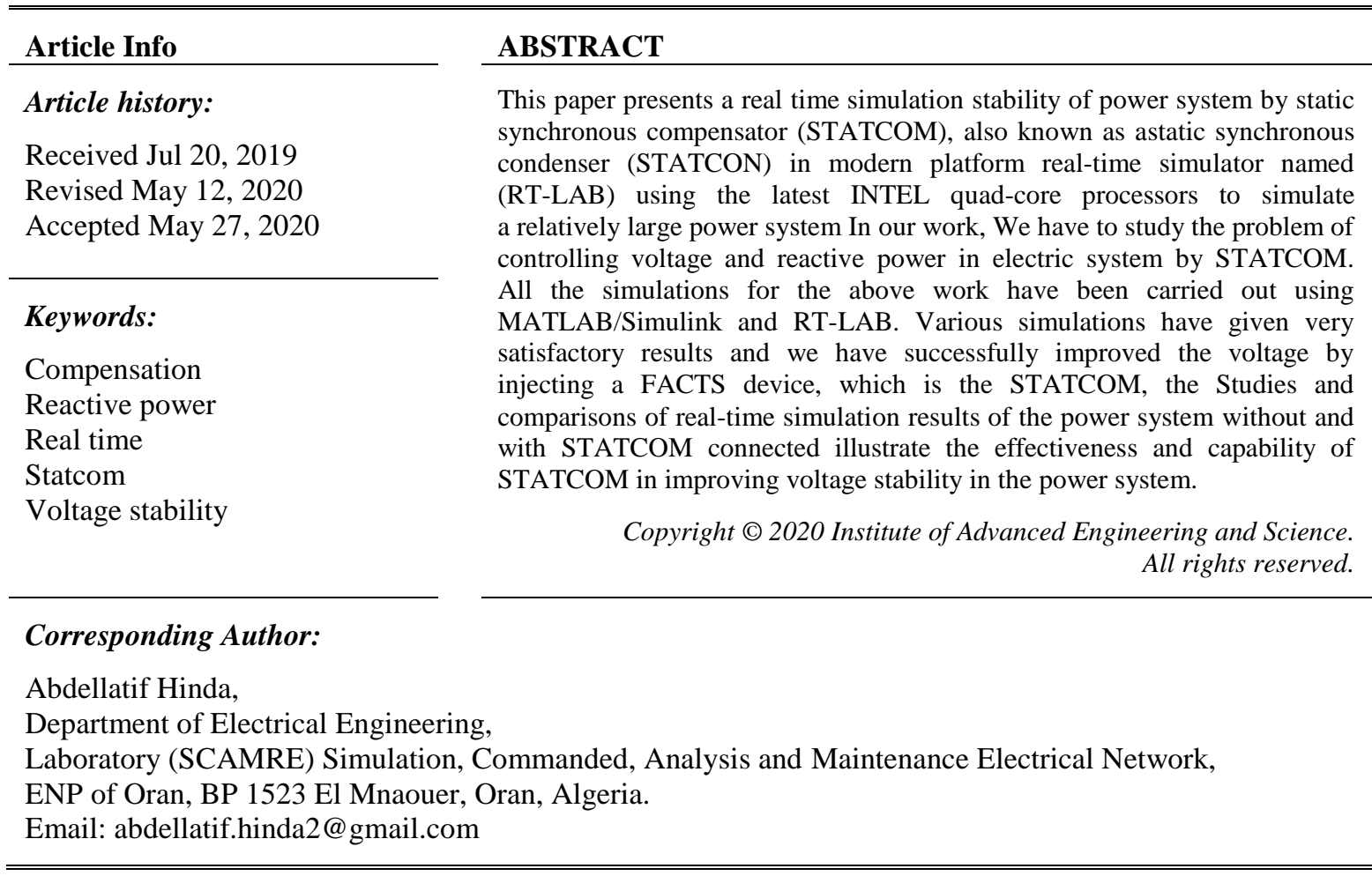

\section{INTRODUCTION}

The management of energy power systems mechanism becomes more complicated because of the continued growth in demand for electricity on the one hand and bad on the other hand some adaptation of electrical values, The voltage stability problems have been serious in industrial and utility power distribution systems, The voltage stability is taking more important nowadays with advanced networks as a result of heavier loadings, moreover, in view of the recent incorporation of more and more intermittent generation in the grid. Solving the voltage stability problems has been the theme of exhaustive exploration for years [1-4].

The voltage stability is defined as the stability of the power system to maintain voltages in a stable state at all buses in the system after being subjected to a disturbance from a known first operating condition $[5,6]$. Voltage instability may result in power system collapse. In the system of power distribution, quick load voltage regulation is necessary to compensate for time varying loads such as fluctuating output power of wind generation systems, electric arc furnaces, and transients on parallel connected loads (e.g., line start of induction motors) [7,8]. Reactive power compensation is an important measure to improve the system voltage stability.

Therefore, the distribution systems need reactive power compensation to maintain the outlet side bus voltage level of the unit, so as to ensure the stable and safe operation of the power system. This difficulty and augment in power supply needs providing the system with recent control systems which contribute to the improvement of the electrical grids performances [9]. The use of flexible AC transmission system (FACTS) controllers in power system has been of worldwide interest for increasing the power transfer capability and enhancing power system stability and controllability due to their speed and flexibility. In addition, converter based FACTS controllers are capable of independently controlling the reactive and 
active power flow in the power system [10]. STATCOM is the member of FACTS device, the static synchronous compensator (STATCOM) is widely used in to compensate fundamental frequency reactive power component, Integration of battery energy storage system (BESS) in to the DC side of the converter makes it possible for a STATCOM to provide also active power support to the network [11]. Investigations have shown the enhanced performance the STATCOM also has the capability for voltage regulation for grid voltage at the common coupling point (PCC) with injecting or absorption a certain amount of reactive power by integrating energy storage into voltage source converters (VSC). STATCOM can control voltage magnitude and, to a small extent, the phase angle in a very short time and therefore, has capability to improve the system $[12,13]$.

With the growing demand for the accuracy of the results in the simulation which is extremely important in analyzing the system performance under diverse operating conditions and control characteristics. In order to guarantee the computer model runs at the same rate as the actual physical system [14], we use a real time simulation platform and to achieve this analysis and precision is using real-time digital simulator by OPAL-RT ${ }^{\mathrm{TM}}$ technologies. This simulator runs on RT-LAB ${ }^{\mathrm{TM}}$ simulation and modeling domain which can perform real time software synchronized simulation as well as real time hardware in loop (HIL) simulation [15]. The techniques to use this real time simulator have been presented in [16] and [17] focusing on the application of RT-Events and Artemis, the Simulink ${ }^{\mathrm{TM}}$ block set models.

For that, one was interested in this paper presents the real time simulation stability of power system. The model is built in Simulink first with the Sim-power system (SPS) blocks and then with the real time simulation in RT-LAB. There are two main contributions here, first with statcom and without statcom.

The paper is organized as follows. First, the statcom model is presented in the first part of section 2. Then control Modeling and controle of STATCOM is presented in later parts of section 2. Then the simulation setup in real time simulator is discussed and the results from Simulink and real time simulations are presented in section 3. Finally, conclusions are described in section 4.

\section{STATIC SYNCHRONOUS COMPENSATOR}

\subsection{Descriptionof statcom}

Because of the high dynamic performance, STATCOM has become one of the most effective pieces of equipment for reactive power compensation [18]. STATCOM is becoming predominant new generation devices for FACTS, which is used to control the voltage through reactive power compensation by either generating or absorbing the reactive power into the grid. The STATCOM is shunt connected at the bus to the power network to provide steady-state voltage regulation and improve the short-term transient voltage stability [19].

Figure 1 shows the basic structure of the STATCOM, which is a shunt connected device which controls the voltage connected to the given reference value with adjusting the voltage and angel of the internal voltage source. A voltage source inverter is used to convert DC input into AC output voltage to compensate the reactive and active power as needed with the grid system. The detailed structure functionality and the detailed structure of the STATCOM can be found in [20].

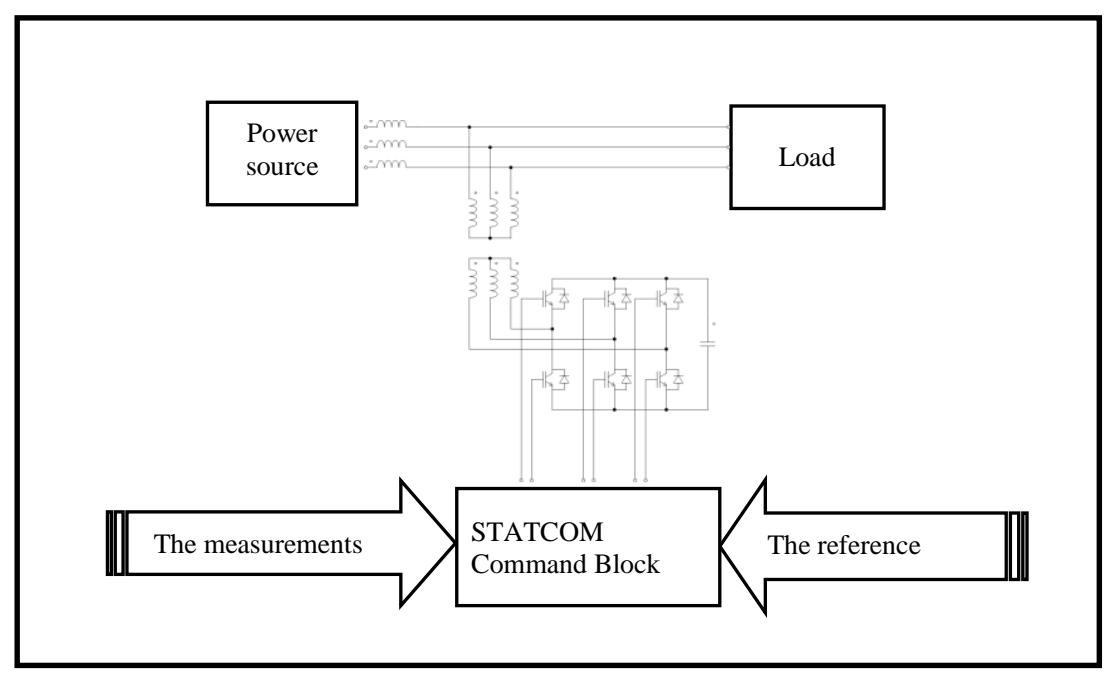

Figure 1. Equivalent circuit STATCOM 


\subsection{Modeling of STATCOM}

The modeling of the STATCOM, though well known, is reviewed in the lines below, for the sake of convenience $[21,22]$. The Figure 2 represented the simplified model circuit of the STATCOM, so this device is a sinusoidal voltage source connected to a network node by the inductance of the coupling transformer. The circuit also includes a resistor in series to represent the ohmic losses of the transformer and the losses in the switches of the inverter.

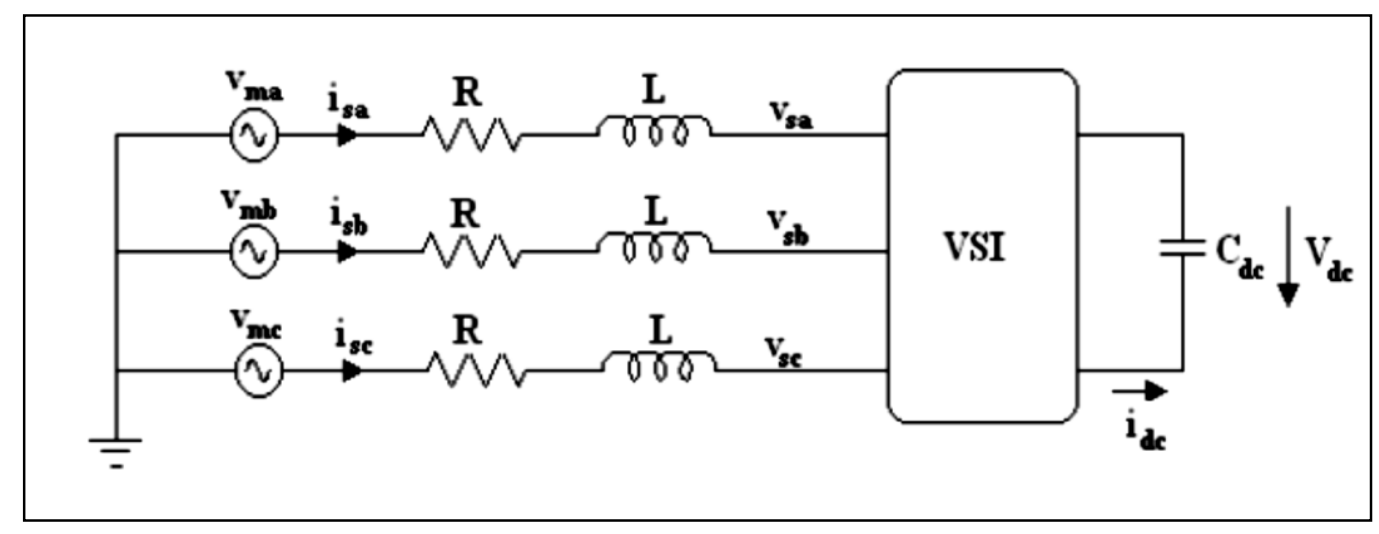

Figure 2. Equivalent circuit STATCOM

The following equations describe the general model of static synchronous condenser is given in (1), reference frame [23].

$$
\frac{d}{d t}\left[\begin{array}{l}
i_{s a} \\
i_{s b} \\
i_{s c}
\end{array}\right]=\left[\begin{array}{ccc}
\frac{-R_{s}}{L_{s}} & 0 & 0 \\
0 & \frac{-R_{s}}{L_{s}} & 0 \\
0 & 0 & \frac{-R_{s}}{L_{s}}
\end{array}\right]\left[\begin{array}{l}
i_{s a} \\
i_{s b} \\
i_{s c}
\end{array}\right]+\left[\begin{array}{ccc}
\frac{1}{L_{s}} & 0 & 0 \\
0 & \frac{1}{L_{s}} & 0 \\
0 & 0 & \frac{1}{L_{s}}
\end{array}\right]\left[\begin{array}{l}
V_{m a}-V_{s a} \\
V_{m a}-V_{s a} \\
V_{m a}-V_{s a}
\end{array}\right]
$$

The complete mathematical model of the STATCOM after transforming park $(\mathrm{d} q)$ frame is obtained as given in (2).

$$
\frac{d}{d t}\left[\begin{array}{c}
I_{s d} \\
I_{s q} \\
U_{d c}
\end{array}\right]=\left[\begin{array}{ccc}
\frac{-R_{s}}{L_{s}} & \omega & \frac{-m}{L_{s}} \cos \theta \\
-\omega & \frac{-R_{s}}{L_{s}} & \frac{m}{L_{s}} \sin \theta \\
\frac{3 m}{2 C} \cos \theta & -\frac{3 m}{2 C} \sin \theta & -\frac{1}{R_{c} C}
\end{array}\right]\left[\begin{array}{c}
I_{s d} \\
I_{s q} \\
U_{d c}
\end{array}\right]+\left[\begin{array}{cc}
\frac{1}{L_{s}} & 0 \\
0 & \frac{1}{L_{s}} \\
0 & 0
\end{array}\right]\left[\begin{array}{l}
V_{d} \\
V_{q}
\end{array}\right]
$$

Where $\theta$ is the VSC firing angle, Linearization of (2) around the operating firing angle $\theta_{0}$, gives a set of linear equations as shown in (3).

$$
\frac{d}{d t}\left[\begin{array}{c}
I_{s d} \\
I_{s q} \\
U_{d c}
\end{array}\right]=\left[\begin{array}{ccc}
\frac{-R_{s}}{L_{s}} & \omega & \frac{-m}{L_{s}} \cos \theta_{0} \\
-\omega & \frac{-R_{s}}{L_{s}} & \frac{m}{L_{s}} \sin \theta_{0} \\
\frac{3}{2} \frac{m}{C} \cos \theta_{0} & -\frac{3}{2} \frac{m}{C} \sin \theta_{0} & -\frac{1}{R_{c} C}
\end{array}\right]\left[\begin{array}{c}
I_{s d} \\
I_{s q} \\
U_{d c}
\end{array}\right]+\left[\begin{array}{ccc}
\frac{1}{L_{s}} & 0 & \frac{m}{L_{s}} U_{d c 0} \sin \theta_{0} \\
0 & \frac{1}{L_{s}} & \frac{m}{L_{s}} U_{d c 0} \cos \theta_{0} \\
0 & 0 & -\frac{3}{2} \frac{m}{C}\left(I_{s d} \sin \theta_{0}+I_{s q} \cos \theta_{0}\right.
\end{array}\right]\left[\begin{array}{c}
V_{d} \\
V_{q} \\
\theta
\end{array}\right]
$$

\subsection{Control of STATCOM}

In the general case, the main objective of the STATCOM control circuit is to correct the power factor under delayed/main loads with the absorption or injection of a current, which is the image of the reactive power of compensation $[24,25]$. These currents are the variables that determine the Statom references from the injected or absorbing powers. The type of control used in this work is the proportionalintegral control (PI-Decoupled). Figure 3 shows the block diagram of the complete circuit consisting of setting a control system of the inverter, and the DC voltage regulator. 


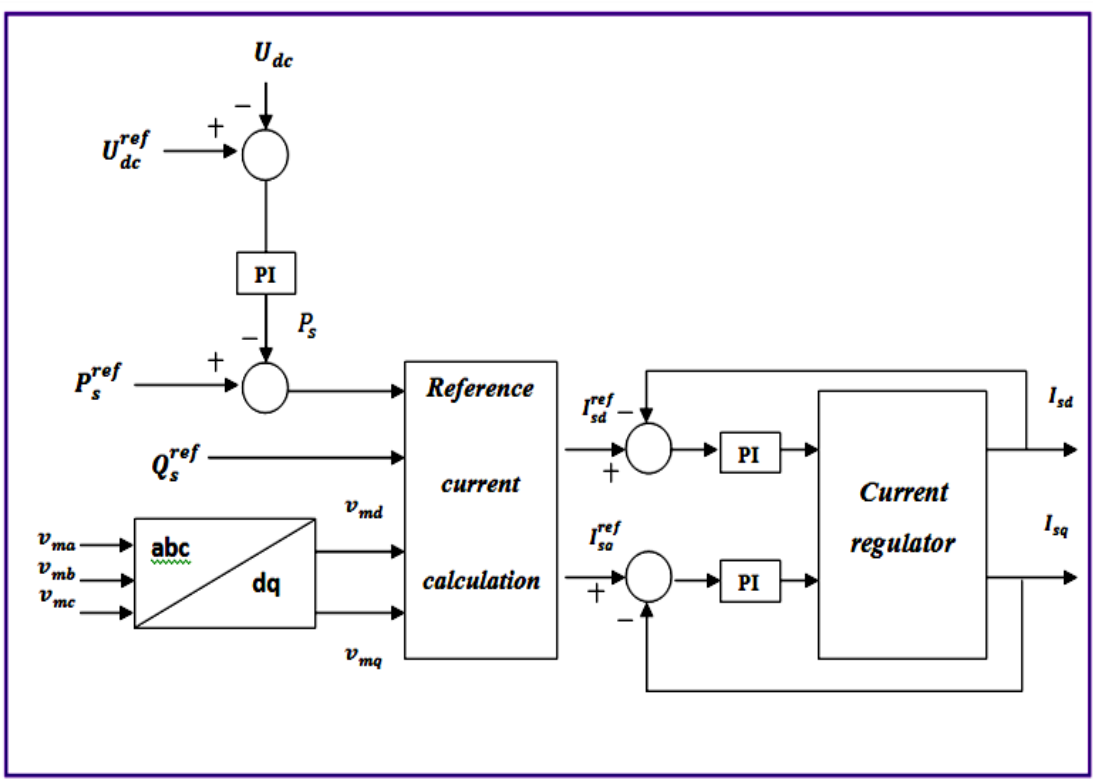

Figure 3. Block diagram of the statcom controller

\section{APPLICATION}

3.1. Description of the network studied

The system studied in the first place is a simple network with a transmission line of $180 \mathrm{~km}$ via a voltage source of $230 \mathrm{kV}$, which is connected to loads (L1, L2, L3), Schematic diagram of the experimental model is shown in Figure 4.

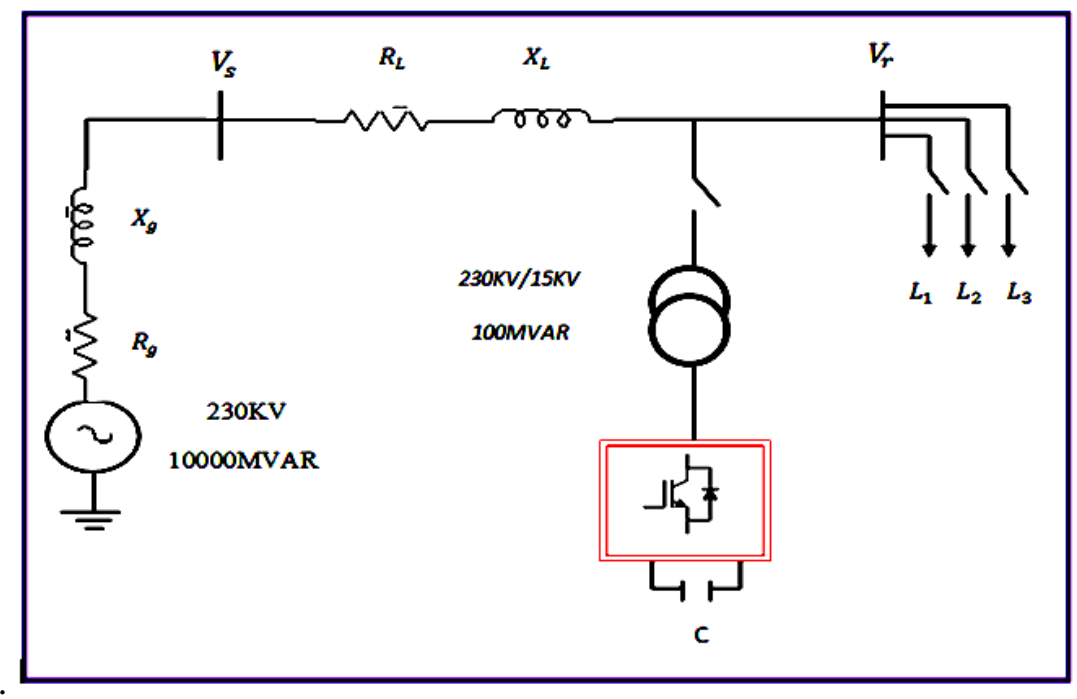

Figure 4. Representation of network simulation

\subsection{The simulator eMEGAsim}

Real-time simulation is a procedure which can be used for validation of the designed system, before the physical execution of an experimental model. In this stage, the prototype is tested to obtain the real-time behavior of the model, so that the testing operations and any adjustments will be made to the model of the prototype. Thus, important amount of time and money can be saved [26]. The simulator eMEGASIM, provided by Opal-RT Technologies, is brought to support the real-time simulation, can be used for, rapid control prototyping and hardware in the loop test [27]. 
RT-LAB is OPAL-RT's flagship product, a real-time simulation provides also special libraries which allow the improvement of the system performance using MATLAB Simulink/SimPowerSystems blocks for real-time simulation. ARTEMIS (advanced real-time electro-mechanical simulator) is a tool integrated into the block set SimPowerSystems of MATLAB Simulink. It provides improved algorithms allowing simulation in realtime, RT-LAB builds parallel tasks from the original Simulink models and run them on each core of the multi-core CPU computer or on the separate computers [28], as shown in Figure 5.

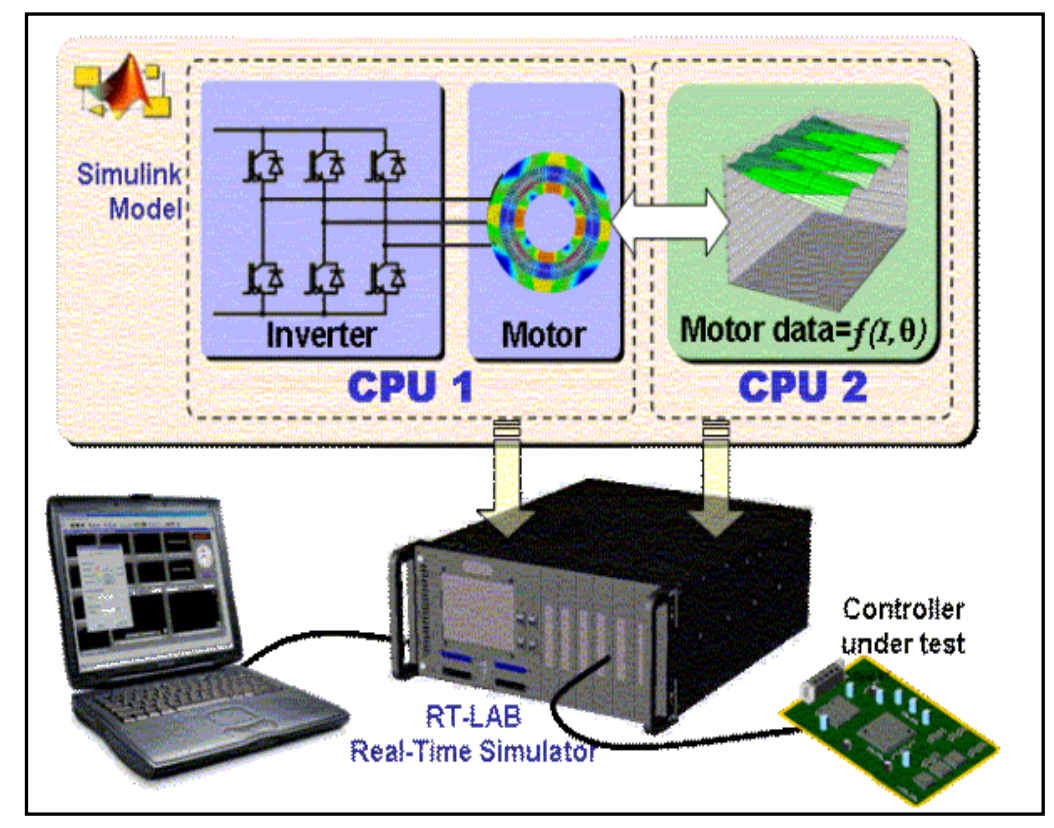

Figure 5. RT-LAB real-time simulator

\subsection{Simulation results and discussion}

\subsubsection{Absence of STATCOM}

Initially the capacitor is charged and STATCOM voltage to these terminals is 1.0pu. The bus bar voltage generating $\mathrm{Vs}=1.0 \mathrm{pu}$, the energy system and vexed on an inductive load L1:(P = 100MW; Q1 80MVAR) in an equilibrium state. In our experiments we will add to the time $(\mathrm{t}=1 \mathrm{~s})$ an inductive load $\mathrm{L} 2:(\mathrm{P}=100 \mathrm{MW}$; $\mathrm{QL}=70 \mathrm{MVAR})$ and the instant $(\mathrm{t}=2 \mathrm{~s})$ is charged over the line by a capacitive load other $\mathrm{L} 3:(\mathrm{P}=30 \mathrm{MW}$; $\mathrm{Qc}=35 \mathrm{MVAR})$ and the time $(\mathrm{t}=3 \mathrm{~S})$ it will disconnect the load $\mathrm{L} 2$ and finally at time $(\mathrm{t}=4 \mathrm{~S})$ all accrued leave only the capacitive load L3 Table 1.

Table 1. The parameters of load and time application

\begin{tabular}{ll}
\hline Time & Load \\
\hline $0 \mathrm{~s}-1 \mathrm{~s}$ & $L 1:\left(P=100 M W ; Q_{l}=80 M V A R\right)$ \\
$1 \mathrm{~s}-2 \mathrm{~s}$ & $L 1:\left(P=100 M W ; Q_{l}=80 M V A R\right)$ \\
& $L 2:\left(P=100 M W ; Q_{l}=70 M V A R\right)$ \\
& $L 1:\left(P=100 M W ; Q_{l}=80 M V A R\right)$ \\
$2 \mathrm{~s}-4 \mathrm{~s}$ & $L 2:\left(P=100 M W ; Q_{l}=70 M V A R\right)$ \\
& $L 3:\left(P=30 M W ; Q_{c}=35 M V A R\right)$ \\
$3 s-4 s$ & $L 1:\left(P=100 M W ; Q_{l}=80 M V A R\right)$ \\
& $L 3:\left(P=30 M W ; Q_{c}=35 M V A R\right)$ \\
$4 s-5 s$ & $L 3:\left(P=30 M W ; Q_{c}=35 M V A R\right)$ \\
\hline
\end{tabular}

Simulation results are shown in the following figures. Figures 6 ( $a$ and $b$ ) shows the voltage drop caused by the inductive load L2 at time $\mathrm{t}=1 \mathrm{~s}$, this fall that will be amortized naturally by connecting the capacitive load L3 at time $\mathrm{t}=2 \mathrm{~s}$ and at time $\mathrm{t}=3 \mathrm{~s}$ by the disconnection of the inductive load L2. Disconnection of inductive loads in the last transition to lead to a significant surge in the voltage bus bar load Vr. 


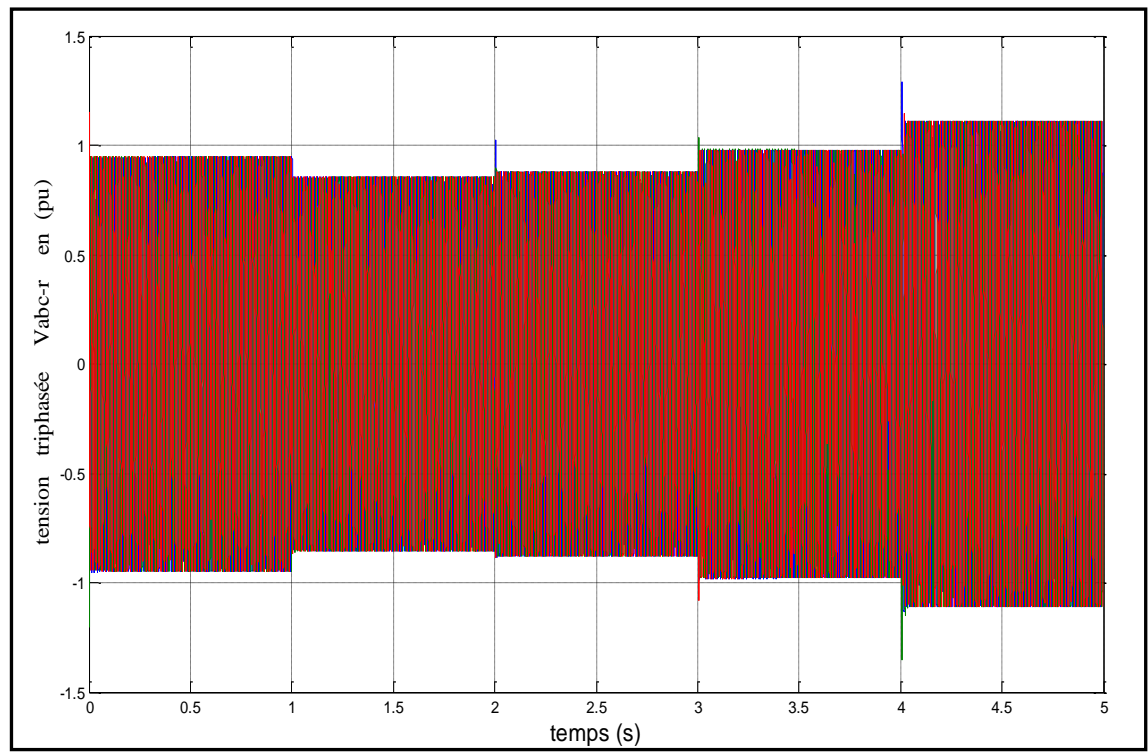

(a)

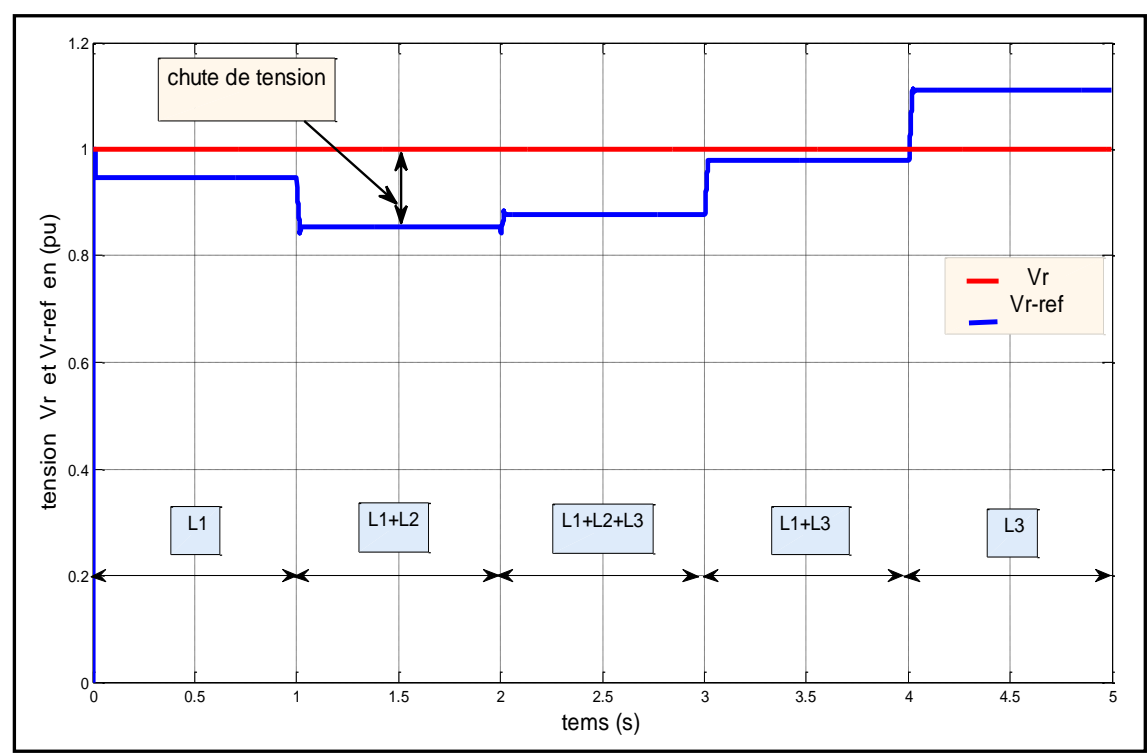

(b)

Figure 6. Tension in line loaded without STATCOM, (a) three-phase voltage $\mathrm{V}_{\text {abc-r }}$ without statcom, (b) voltage $\mathrm{Vr}$ calculated without statcom

\subsubsection{Presence of STATCOM}

By taking these tests with the same loads on the network associated with a STATCOM to the bus bar reception (charge) we find. Figures 7 ( $a$ and $b$ ) shows that the voltage regulated at the starting value $\mathrm{Vr} \approx 1.0 \mathrm{pu}$. From the simulation results it can be said that the STATCOM plays an essential role in the improvement of the power factor and the regulation of the voltage of the network.

The STATCOM injects a current Isq (Isd $\approx 0$ ) which increases by charging the line more and more with inductive loads L1 + L2 Figure 8 . The direction of the reactive current Ishq injected by the STATCOM to the network positive in inductive mode $\mathrm{t}(0 \mathrm{~s}-4 \mathrm{~s})$ indicating that the compensator delivers reactive power to the network, and negative in the capacitive charge phase $\mathrm{t}(4 \mathrm{~s}-5 \mathrm{~s})$ for show the absorption of reactive energy from the network by STATCOM Figure 9. The currents in this device, STATCOM, Isd and Isq follow their magnitudes references which are calculated from the reference and powers necessary to compensate the reactive power in the line and keep the voltage bus bar (Vr) which validates the proper functioning of proportional integral controllers "PI" placed in the Watt-Var decoupled model used. 
Table 2 shows at the time $(t=0 S)$ the STATCOM injects a small amount of reactive power Qs of about $\mathrm{Qs} \approx 35 \mathrm{MVAR}$ to raise the voltage $\mathrm{Vr}$ to $1.0 \mathrm{pu}$. But after the commissioning of the load L1 + L2 $(\mathrm{t}=2 \mathrm{~s})$, reactive power is necessary for clearing, and the STATCOM in a capacitive mode injects about $\mathrm{Qs} \approx 95 \mathrm{MVAR}$. By connecting the capacitive load to $(\mathrm{t}=3 \mathrm{~s})$ reactive power supplied by the STATCOM decreases because of the capacitive effect of that load on the transmission line. At the time $(t=3 \mathrm{~s})$ it will disconnect the load L2 STATCOM injects a small amount of reactive power Qs = 15MVAR because of the capacitive effect of the load on the line L3 transport. In the last step the capacitive load connected to the line causes an over voltage to the bus bar load Vr and that the STATCOM operates in inductive mode and absorb reactive power from the network to maintain the profile of the voltage $\mathrm{Vr}$ à $1 \mathrm{pu}$, we see thus the voltage Vs becomes lower than the voltage Vr.

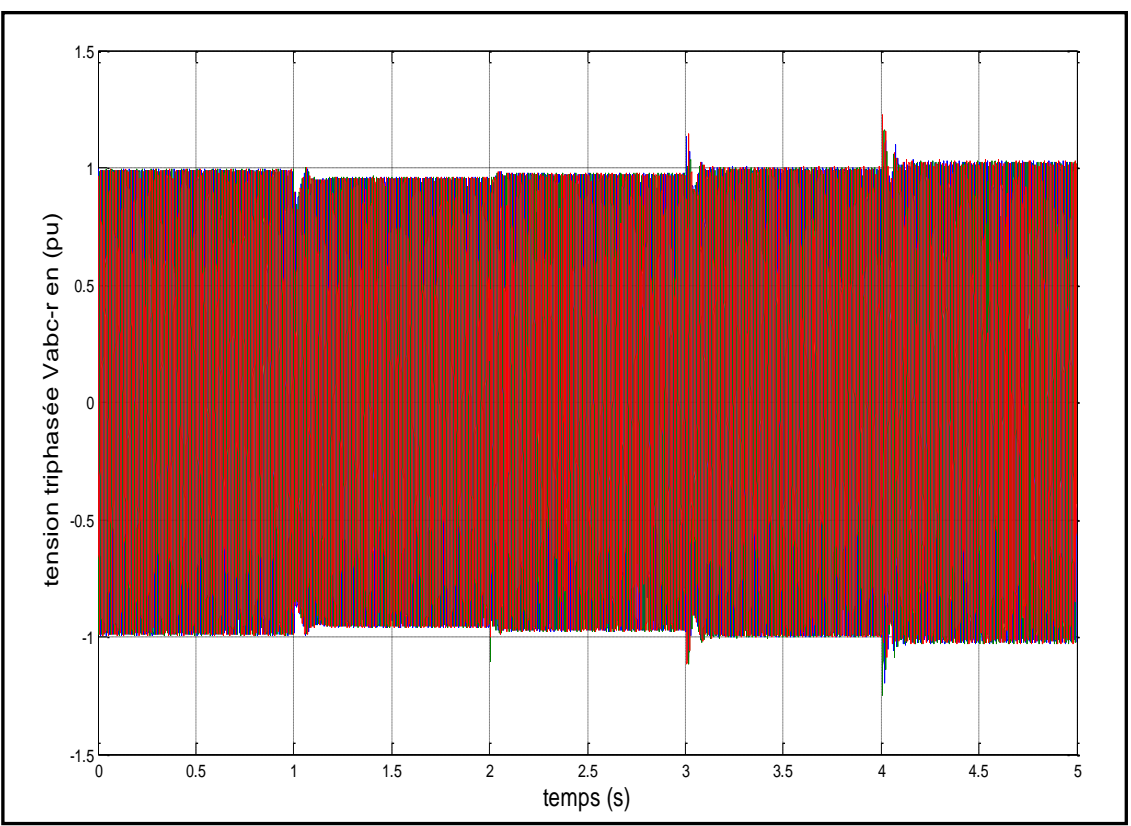

(a)

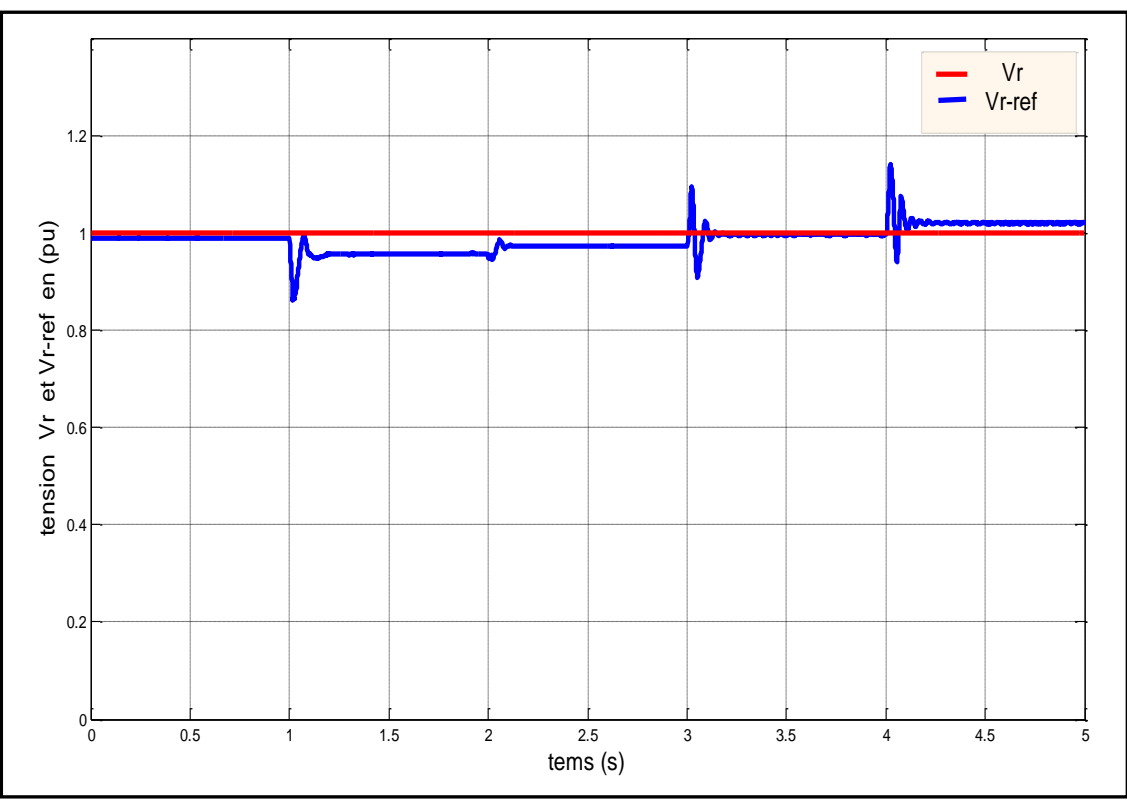

(b)

Figure 7. Tension in line loaded with STATCOM, (a) three-phase voltage $\mathrm{V}_{\text {abc-r }}$ with the statcom, (b) voltage $\mathrm{Vr}$ calculated with the statcom 


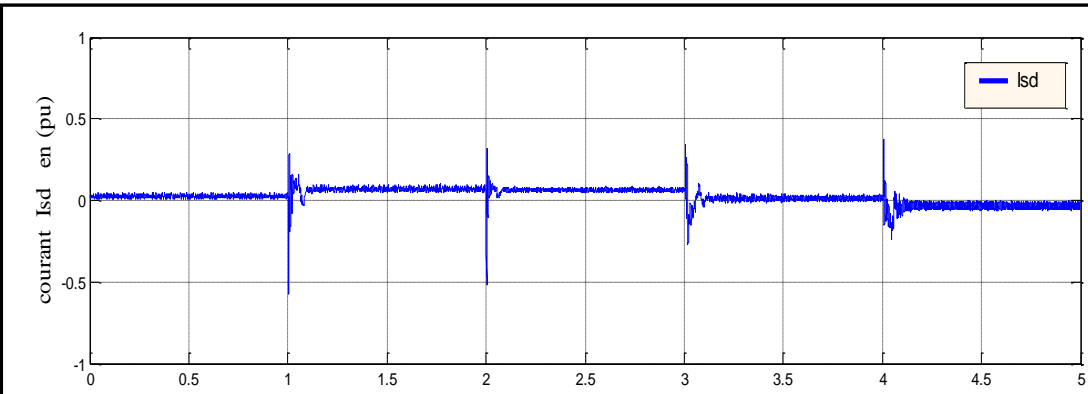

(a) - courant actif Isd du statcom

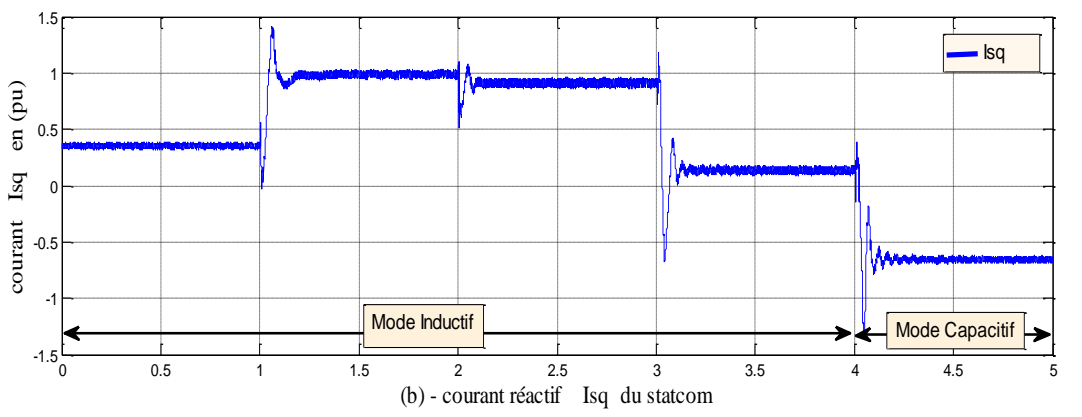

Figure 8. The current of STATCOM

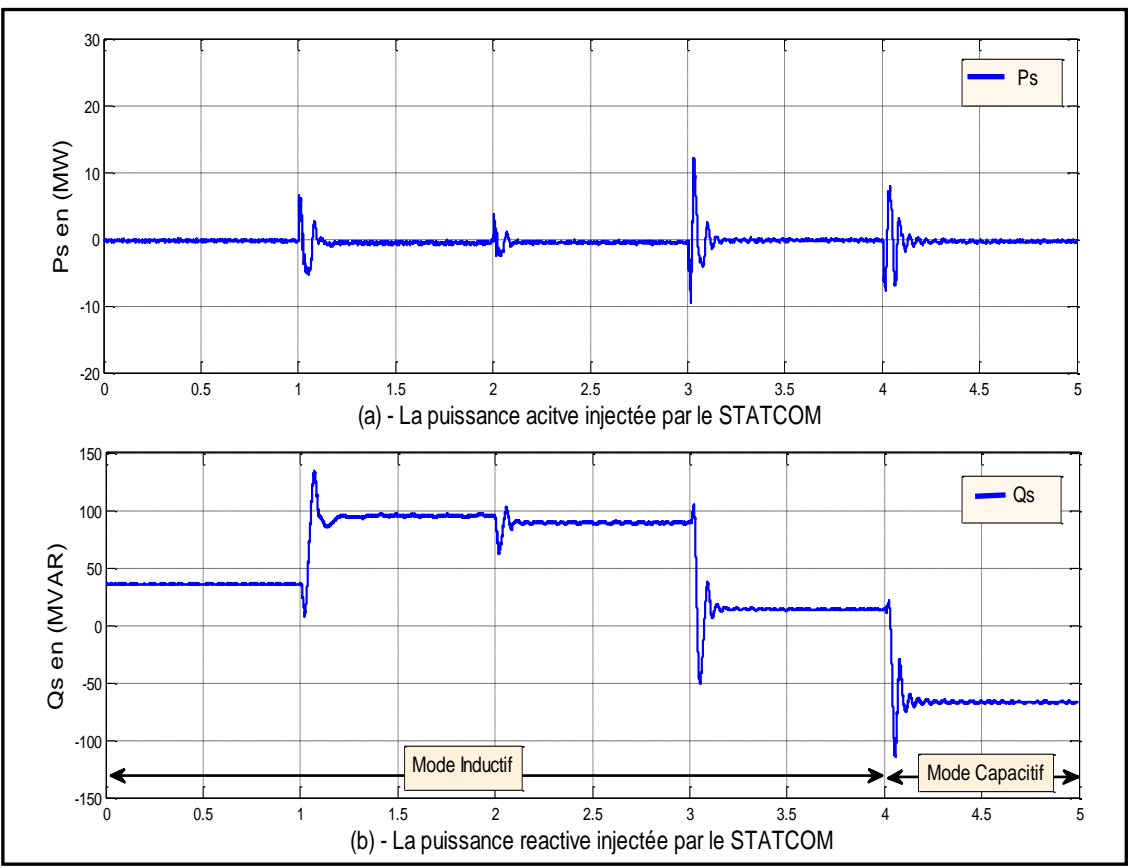

Figure 9. Active and reactive power injected by the STATCOM

Table 2. Dynamic response of the STATCOM for variations loads

\begin{tabular}{ccccc}
\hline Time & Load & With Statcom & \multicolumn{2}{c}{ Without Statcom } \\
\cline { 3 - 5 } & & Vr tension in $(\mathrm{pu})$ & Vr tension in $(\mathrm{pu})$ & $\begin{array}{c}\text { Reactive Power injected by } \\
\text { the Statcom en MVAR }\end{array}$ \\
\hline $0 \mathrm{~s}-1 \mathrm{~s}$ & $\mathrm{~L}_{1}$ & 0,95 & 0,99 & 35 \\
$1 \mathrm{~s}-2 \mathrm{~s}$ & $\mathrm{~L}_{1}+\mathrm{L}_{2}$ & 0,85 & 0,96 & 95 \\
$2 \mathrm{~s}-3 \mathrm{~s}$ & $\mathrm{~L}_{1}+\mathrm{L}_{2}+\mathrm{L}_{3}$ & 0,87 & 0,98 & 90 \\
$3 \mathrm{~s}-4 \mathrm{~s}$ & $\mathrm{~L}_{1}+\mathrm{L}_{3}$ & 0,98 & 1 & 15 \\
$4 \mathrm{~s}-5 \mathrm{~s}$ & $\mathrm{~L}_{3}$ & 1,1 & 1,02 & -65 \\
\hline
\end{tabular}


The effect of the compensation of reactive power directly affects the transit of the active power as shown in Figure 10. The supply of reactive power at the point of consumption allows greater transit active power minimizing the reactive power flow in the transmission line. The voltage of the bus bar or the controlled device and is connected to the value of the starting voltage could $\operatorname{Vr} \approx 1.0$. The static error between the voltage $\mathrm{Vr}$ and the regulated reference voltage $\mathrm{V}=1.0 \mathrm{pu}$ is due to simplification carried out in the expression for the reactive power reference $Q_{S}^{r e f}=\frac{V_{S * \Delta V}}{X}$ requested to be injected by the STATCOM controller Figure 10.

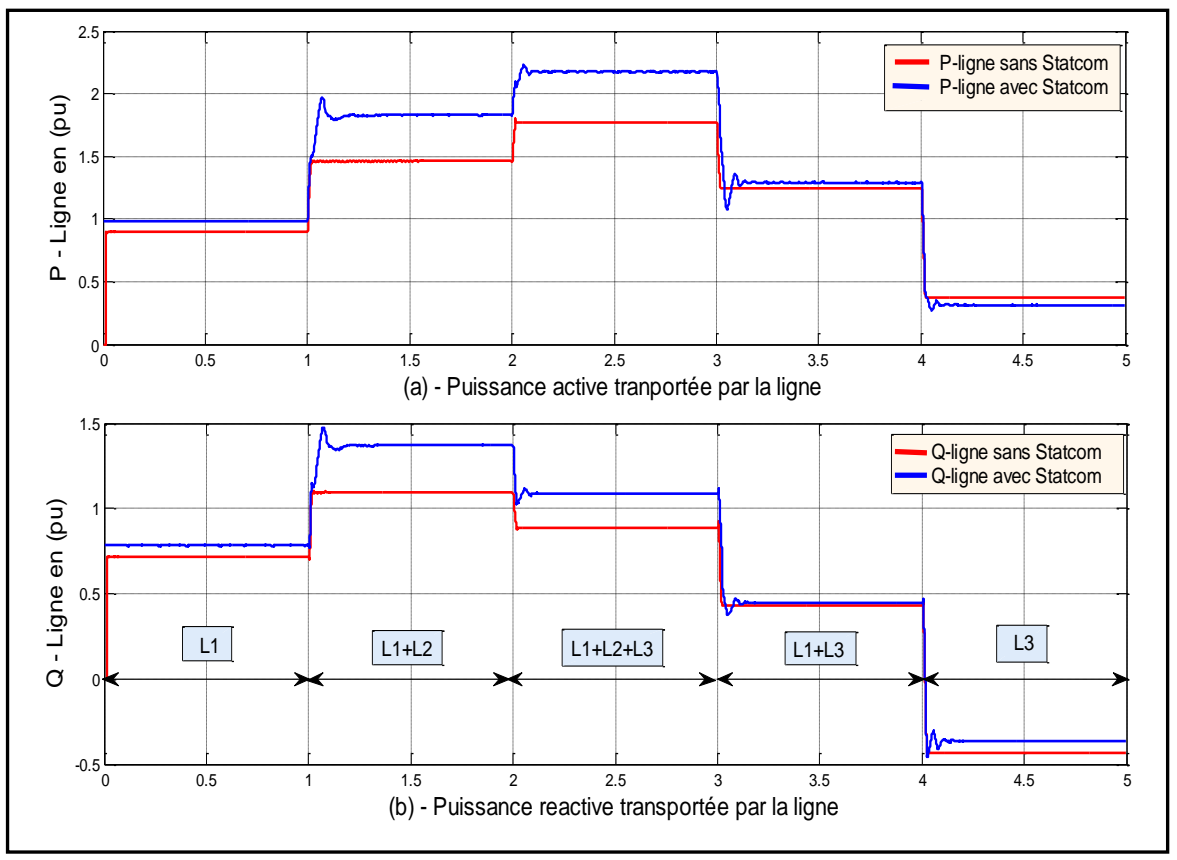

Figure 10. Powers carried by the line with and without Statcom

\section{CONCLUSION}

With the simulations of the statcom in the power system in MATLABTM/Simulink and RT-LAB environment, it can be concluded that RT-LAB is applicable and can achieve the goal of real-time simulation. The simulation results without and with STATCOM connected to the system confirm that STATCOM can be used to improve the voltage stability of the power system. The STATCOM device is providing or consuming dynamic reactive power on the network. This has the effect of increasing or decreasing the amplitude of the voltage at the connection point, and therefore the maximum transferable active power. Simulation results verified the effectiveness of the control strategy that allows independent control and decoupled active and reactive power of these devices by minimizing the interaction effect between these powers.

\section{REFERENCES}

[1] A. Movahedia, A. H. Niasara, G. B. Gharehpetianb, "Designing SSSC, TCSC, and STATCOM controllers using AVURPSO, GSA, and GA for transient stability improvement of a multi-machine power system with PV and wind farms," International Journal of Electrical Power \& Energy Systems, vol. 106, pp 455-466, Mar. 2019

[2] A. Oukennou, et al., "Coordinated Placement and Setting of FACTS in Electrical Networks based on eqKalai smorodinsky Bargaining Solution and Voltage Deviation Index," International Journal of Electrical and Computer Engineering (IJECE), vol. 6, no. 6, pp. 4079-4088, 2018.

[3] I. Alhamrouni, W. Wahab, M. Salem, N. H. A. Rahman, and L. Awalin, " Modeling of micro-grid with the consideration of total harmonic distortion analysis," Indonesian Journal of Electrical Engineering and Computer Science, vol. 15, no. 2, pp. 581-592, 2019.

[4] H. Bakir, A. A. Kulaksiz, "Modelling and voltage control of the solar-wind hybrid micro-grid with optimized STATCOM using GA and BFA," Engineering Science and Technology, an International Journal, vol. 23, no. 3, pp. 576-584, Jun. 2020.

[5] Prabha K., John P., Vijay V., and Göran A., "Definition and classification of power system stability," IEEE Trans. Power Syst., vol. 19, no. 2, pp. 1387-1401, Aug. 2004. 
[6] Bhaskara R., "Study of Voltage Stability Indices Suitable for Online Applications," International Journal of Engineering and Applied Sciences, vol. 1, no. 3, pp. 30-33, Dec. 2014.

[7] Jain A., Joshi K., Behal A., and Mohan N.,"Voltage regulation with STATCOMs: modeling, control and results," IEEE Transaction of Power Delivery, vol. 21, no. 2, pp. 726-735, 2006.

[8] M. Gutierrez, G. Venkataramanan, and A. Sundaram, "Solid state flicker controller using a pulse width modulated AC-AC converter," Proc. 35th IEEE Industry Applications Soc. Annu. Meeting, vol. 5, pp. 3158-3165, 2000.

[9] G. A. Salman, M. H. Ali, and A. N. Abdullah, "Implementation Optimal Location and Sizing of UPFC on Iraqi Power System Grid $(132 \mathrm{kV})$ Using Genetic Algorithm," International Journal of Power Electronics and Drive System (IJPEDS), vol. 9, no. 4, pp. 1607-1615, 2018.

[10] A. Hinda, M. Khiat, and Z. Boudjema, "Advanced control scheme of a unifiedpower flow controller using sliding mode control," International Journal of Power Electronics and Drive System (IJPEDS), vol. 11, no. 2, pp. 625-633, 2020.

[11] N. Mithulananthan., C. A. Canizares., J. Reeve., and G. J. Rogers., "Comparison of PSS, SVC and STATCOM controllers for damping power system oscillations," IEEE Transactions on Power Systems, vol. 18, pp. 786-792, May 2003.

[12] V. K. Chandrakar., and A. G. Kothari, "Comparison of RBFN based STATCOM, SSSC and UPFC Controllers for Transient Stability improvement," In Power Systems Conference and Exposition, PSCE '06, pp. 784-791, 2006.

[13] M. M. Hussaini., and R. Anita., "The Study of Dynamic Performance of Wind Farms with the Application Trends in Engineering," International Journal of Recent Trends in Engineering, vol. 2, no. 6, pp. 158-160, 2009.

[14] S. Mohan Krishna, and J.L. Febin Daya, "MRAS speed estimator with fuzzy and PI stator resistance adaptation for sensorless induction motor drives using RT-lab," Recent Trends in Engineering and Material Sciences, vol. 8, pp. 121-126, Sep. 2016

[15] R. Maharjan and S. Kamalasadan, "Real-time simulation for active and reactive power control of doubly fed induction generator," 2013 North American Power Symposium (NAPS), Manhattan, KS, pp. 1-6, 2013.

[16] C. Dufour and J. Belanger, "A real-time simulator for doubly fed induction generator-based wind turbine applications," 2004 IEEE 35th Annual Power Electronics Specialists Conference (IEEE Cat. No.04CH37551), Aachen, Germany, vol. 5, pp. 3597-3603, 2004.

[17] C. Dufour, S. Abourida and J. Belanger, "Hardware-In-the-Loop Simulation of Power Drives with RT-LAB," 2005 International Conference on Power Electronics and Drives Systems, Kuala Lumpur, pp. 1646-1651, 2005.

[18] S. Gautam, C. Pang and L. Yang, "Impacts of FACTS device on wind farm protection: Comparison between STATCOM and UPFC," 7th International Conference on Information and Automation for Sustainability, Colombo, pp. 1-6, 2014.

[19] W. Qiao, G. K. Venayagamoorthy and R. G. Harley, "Real-Time Implementation of a STATCOM on a Wind Farm Equipped with Doubly Fed Induction Generators," in IEEE Transactions on Industry Applications, vol. 45, no. 1, pp. 98-107, Jan-Feb. 2009,

[20] M. A. Kamarposhti, M. Alinezhad, H. Lesani and N. Talebi, "Comparison of SVC, STATCOM, TCSC, and UPFC controllers for Static Voltage Stability evaluated by continuation power flow method," 2008 IEEE Canada Electric Power Conference, Vancouver, BC, pp. 1-8, 2008.

[21] M. Darabiana, A. Jalilvanda, A. Ashourib, A. Bagheri, "Stability improvement of large-scale power systems in the presence of wind farms by employing HVDC and STATCOM based on a non-linear controller," International Journal of Electrical Power \& Energy Systems, vol. 120, Sep. 2020.

[22] Liu, F., Mei, S., Lu, Q., Ni, Y., Wu, F.F., Yokoyama, A., "The nonlinear internal control of STATCOM: theory and application," In International Journal of Electrical Power and Energy Systems, vol. 25, no. 6, pp. 421-430, 2003.

[23] N. Voraphonpiput and S. Chatratana, "STATCOM Analysis and Controller Design for Power System Voltage Regulation," 2005 IEEE/PES Transmission \& Distribution Conference \& Exposition: Asia and Pacific, Dalian, pp. 1-6, 2005.

[24] M. Y. Suliman, "Voltage profile enhancement in distribution network using static synchronous compensator STATCOM," International Journal of Electrical and Computer Engineering (IJECE), vol. 10, no. 4, pp. 3367-3374, 2020.

[25] W. Meng, G. Qinxiang, C. Leiting, L. Liqiang and Z. Caiyun, "Mathematical Model and Control Strategy of UPFC," 2014 Sixth International Conference on Measuring Technology and Mechatronics Automation, Zhangjiajie, pp. 391-393, 2014.

[26] Aurel B., Radu T., Radu M., Adrian G., Dan R., "Hysteresis Current Control of the Single-Phase Voltage Source Inverter Using eMEGAsim Real-Time Simulator Advances," Electrical and Computer Engineering, vol. 15, no. 3, pp. 99-104, 2015.

[27] X. Zhang, F. Zheng, J. Zhang and J. Huang, "Study on the grid adaptability test for photovoltaic inverter based on RT-LAB simulator," International Conference on Renewable Power Generation (RPG 2015), Beijing, pp. 1-5, 2015.

[28] K. Benaama, M. Khiat, S. Barkat, "Real time modeling and control of a wind farm connected to a multi-bus network under faulty conditions" ISA Transactions, vol. 93, pp. 384-398, Oct. 2019. 